\title{
Knowledge and prevalence of risk factors for arterial hypertension and blood pressure pattern among bankers and traffic wardens in Ilorin, Nigeria
}

\author{
AG Salaudeen ${ }^{1}$, OI Musa ${ }^{1}$, OA Babatunde 2 , OA Atoyebi ${ }^{2}$, KA Durowade ${ }^{2}$, \\ LO Omokanye ${ }^{3}$
}

\begin{abstract}
1. Department of Epidemiology and Community Health, University of Ilorin, Ilorin, Nigeria

2. Department of Community Medicine, Federal Medical Center, Ido-Ekiti, Nigeria

3. Department of Obstetrics and Gynaecology, University of Ilorin, Ilorin, Nigeria
\end{abstract}

\begin{abstract}
Background: High job strain, mental stress, sedentary lifestyle, increase in BMI are among the factors associated with significantly higher incidence of hypertension. The job of bank employees is both sedentary in nature and accompanies high mental stress. The aim of this study is to assess the level of knowledge of risk factors among respondents and to compare the blood pressure pattern of bankers and traffic wardens.

Methodology: The study design is a descriptive cross-sectional conducted among bankers and traffic wardens in Ilorin to determine the pattern and knowledge of blood pressure. Self-administered questionnaires, weighing scale (Omron Digital scale), stadiometer and sphygmomanometer were used as the research instruments. Simple random sampling was used to select respondents involved in the study.

Results: The prevalence of hypertension in this study was $34.4 \%$ in bankers and $22.2 \%$ in traffic wardens. The risk factors the bankers commonly had knowledge of are alcohol, obesity, high salt intake, certain drugs, stress, emotional problems and family history while the traffic wardens commonly had knowledge of all these in addition to cigarette smoking. Also, more bankers $(32.2 \%)$ than traffic wardens $(13.3 \%)$ were smoking cigarette and more of these cigarette smokers that are bankers $(17.8 \%)$ had elevated blood pressure compared to the traffic wardens $(3.3 \%)$.

Conclusion: Workers in the banking industry as well as traffic wardens should be better educated about the risk factors of hypertension and bankers should be encouraged to create time for exercise.
\end{abstract}

Key words: Hypertension, risk factors, bankers, traffic wardens

DOI: http://dx.doi.org/10.4314/ahs.v14i3.14

\section{Introduction}

Hypertension is becoming a public health emergency worldwide especially in developing countries where it is projected that by year 2025 , there will be an $80 \%$ increase in the number of hypertensive individuals. ${ }^{1}$ Studies show that the prevalence of hypertension might be associated with job related factors. ${ }^{2}$ Jobs with high mental stress and low physical activity as found in banking are a significant risk factor for hypertension. ${ }^{3}$ Hypertension is a controllable disease and a small decline of $2 \mathrm{mmHg}$ in blood pressure population-wide can prevent 151,000 stroke cases. $^{3}$

\section{Corresponding author: \\ Dr. A. G. Salaudeen \\ Department of Epidemiology and \\ Community Health, \\ University of Ilorin, Ilorin, Nigeria \\ Phone Number: 08036708106 \\ E-mail: adekunlesalaudeen@yahoo.com}

Hypertension is now a burden to the society and several modifiable risk factors contribute directly to this burden. ${ }^{4}$ High job strain has been associated with significantly higher diastolic blood pressure of $4.5 \mathrm{mmHg}$ during working hours ${ }^{5}$ and it has been proven that chefs showed one risk factor more than office workers. ${ }^{6}$ There is also a dearth of information on diet related chronic diseases in West Africa creating a challenge for comparative research for intervention purposes. ${ }^{7}$ There are evidences that long term mental stress is associated with hypertension but more research is needed in this area. ${ }^{3}$ The job of bank employees is both sedentary in nature and accompanies high mental stress. ${ }^{3}$

A comparison among two occupational groups (chefs and office workers) showed that $62.2 \%$ and $58.3 \%$ of the chefs and office workers were overweight respectively. ${ }^{6}$ Smoking habit is another risk factor reported in 23.9\% of respondents the Polish study. ${ }^{8}$ In the Brazilian study, alterations in the blood glucose levels were identified in $49 \%$ of respondents, while high level of cholesterol and triglycerides were seen in $7 \%$ and $11 \%$ respectively, 
of industry workers. ${ }^{9,10}$

The extent of knowledge of workers about hypertension would determine how far they will go to seek intervention for the disease. Research has shown that people generally have varying levels of knowledge of the risk factors and management options for hypertension. A study carried out in North Carolina, USA by Viera et al in 2008 revealed that $22 \%$ of the known hypertensive primary care patients sampled either were not sure whether anything could be done to prevent high blood pressure or believed that there is nothing that can be done. ${ }^{11}$ Several other factors have been shown to affect the knowledge of hypertension risk factors among respondents. In Brazil, Borges et $\mathrm{al}^{12}$ in a 2009 study on knowledge on risk factors for chronic diseases constructed a knowledge score and the highest mean score was observed for inadequate diet (5.3), smoking (5.1), sedentary lifestyle (4.7), and alcohol abuse (4.5). This study also showed that higher socioeconomic status, level of schooling and age group are important factors affecting the knowledge of risk factors for hypertension.

The prevalence of hypertension is increasing in various communities. The prevalencein bankers and other similar occupations of sedentary nature has been found to be higher. ${ }^{3}$ Maroof et al in 2006 conducted a study which showed a prevalence of $69.5 \%$ among bankers in a district in India. ${ }^{3}$ In this study, hypertension was associated with mental stress. Job strain has also been similarly found to be significantly related to hypertension with a odds ratio of $1.18 .{ }^{13}$ Employment (white collar v blue collar), marital status, family history of hypertension, cigarette smoking, alcohol intake, physical activity and Body Mass Index (BMI) are among the factors contributing to the development of hypertension. ${ }^{13-19}$ Stratified analysis done by Tatsumi et al in Japan showed significant excess risks in the subordinate groups, blue collar workers, less educated workers and older age groups. ${ }^{13}$ In a similar study, Martinez et al in Brazil found intense work stress, sedentary lifestyle, male gender, age $>40$, alcohol consumption, BMI above 25, altered cholesterol and altered triglycerides were associated with hypertension ${ }^{14}$ with statistical significance $(\mathrm{p}<0.0001)$.

The aim of this study is to assess the level of knowledge of risk factors among respondents and to compare the blood pressure pattern of bankers and traffic wardens.

\section{Methods}

The study design is a descriptive cross-sectional conducted among bankers and traffic wardens in Ilorin to determine the pattern and knowledge of blood pressure. Ilorin is the capital of Kwara State located in north central Nigeria. Self-administered questionnaires, weighing scale (Omron Digital scale), stadiometer and sphygmomanometer were used as the research instruments. Advocacy and introductory visits was paid to the Kwara State Commissioner of Police and bank managers of the selected banks. Simple random sampling technique using table of random numbers was used to select the traffic wardens. This was done over a period of one week to accommodate people involved in different shifts. Simple random sampling was used to select 18 out of 39 commercial banks in Ilorin. In each bank, simple random sampling was used to select 10 respondents. In all, 360 respondents comprising 180 bankers and same number for traffic warden were involved in the study.

Analysis was done using Statistical Package for Social sciences (SPSS) software version 14.0. Verbal consents were gotten from each respondent before the questionnaires were administered. Respondents were also guaranteed of full privacy of information provided and participation was voluntary. Ethical approval for the study was obtained from the Ethical Committee of the Department of Epidemiology and Community Health, University of Ilorin, Nigeria.

\section{Blood Pressure Measurement}

The mercury sphygmomanometer was used in the measurement of the blood pressure of the respondents. Each subject was made seated quietly for at least 5 minutes in a chair (rather than on an exam table) with their backs supported and their arms bared and supported at heart level. It was ensured that they refrain from smoking or ingesting caffeine during the 30 minutes preceding the measurement.

The use of a cuff that is appropriate to the size of the upper right arm was ensured. The right arm was preferred to enhance consistency and comparison with the standard tables. The use of an appropriate cuff size was ensured with the use of a cuff having a bladder width that is approximately $40 \%$ of the arm circumference midway between the olecranon and the acromion. This is because an excessively large bladder may lead to falsely low readings in the range of 10 to 30 $\mathrm{mm} \mathrm{Hg}$. It was ensured that the bladder within the cuff encircles at least $80 \%$ of the arm.

The bell of the stethoscope was then placed over the brachial artery pulse, proximal and medial to the cubital fossa, and below the bottom edge of the cuff (i.e. 
about $2 \mathrm{~cm}$ above the cubital fossa).The cuff was then inflated to $30 \mathrm{~mm} \mathrm{Hg}$ above palpated SBP and deflated at a rate of 2 to $3 \mathrm{~mm} \mathrm{Hg} /$ second. Both systolic blood pressure (SBP) and diastolic blood pressure (DBP) were recorded. The first appearance of sound (phase 1) was used to define SBP. The disappearance of sound (phase 5) was used to define DBP among the respondents. Two or more readings separated by 2 minutes were taken per subject and averaged. For some subjects whose first two readings differ by more than $5 \mathrm{~mm} \mathrm{Hg}$, additional readings were obtained and averaged.

\section{Measurement of Weight}

The Omron Digital weighing scale was placed on a hard-floor surface (not on a floor which is carpeted or otherwise covered with soft material). Calibration was ensured at the beginning and end of each examining day. Participants were asked to remove their heavy outer garments (jacket, coat, trousers, skirts, e.tc.) and shoes. For subjects that declined to remove trousers or skirt, they were encouraged to make them empty their pockets and record the fact in the data collection form. The participant stands in the centre of the platform; weight distributed evenly to both feet, standing off the centre may affect the result.

\section{Measurement of Height}

The height of the participants was determined with the use of the portable stadiometre. Each participant was asked to remove head gear or cap. The height rule is taped vertically to a hard flat wall surface with the base at floor level. Participants were asked to remove their shoes, heavy outer garments, and hair ornaments and were asked to stand with their back to the height rule. The back of the head, back, buttocks, calves and heels should be touching the upright, feet together. The top of the external auditory meatus (ear canal) was at the same level with the inferior margin of the bony orbit (cheek bone). The participants were asked to look straight. The head piece of the stadiometer or the sliding part of the measuring rod is lowered so that the hair (if present) is pressed flat and the measurement was taken in meters.

\section{Results}

Most (68.9\%) of the bankers interviewed were in their twenties while $27.2 \%$ of the traffic wardens fell within this age group. About half of the traffic wardens $(49.4 \%)$ were in the $30-39$ age group while $26.7 \%$ of the bankers were in their thirties. There were more male respondents than females with the bankers' group being made up of 124 males $(68.9 \%)$ and 56 females $(31.1 \%)$, and the traffic warden group being made up of 113 males (62.8\%) and 67 females (37.2\%). Most of the respondents in the banking profession were single $(77.2 \%)$ while most of the traffic wardens were married (77.8\%). The respondents' religion is also skewed with more bankers $(72.8 \%)$ being Christians and $76.1 \%$ of the traffic wardens as well.

Table 1: Socio-demographic Characteristics of Respondents

\begin{tabular}{llc}
\hline Variable & & Frequency (\%) \\
\hline & & \\
Age Group (years) & Bankers (n=180) & Traffic Wardens $(\mathbf{n}=\mathbf{1 8 0})$ \\
$20-29$ & $124(68.9)$ & $49(27.2)$ \\
$30-39$ & $48(26.7)$ & $89(49.4)$ \\
$40-49$ & $6(3.3)$ & $30(16.7)$ \\
$\geq 50$ & $2(1.1)$ & $12(6.2)$
\end{tabular}

\section{Gender}

Female

Male

$56(31.1)$

$124(68.9)$

$67(37.2)$

$113(62.8)$

Marital Status

$\begin{array}{lcc}\text { Single } & 139(77.2) & 37(20.6) \\ \text { Married } & 34(18.9) & 140(77.8) \\ \text { Divorced } & 7(3.9) & 3(1.6)\end{array}$

\section{Religion}

Christianity

Islam

$131(72.8)$

$137(76.1)$

$49(27.2)$ 
Varying levels of knowledge of risk factors exist among respondents. Most of the bankers (96.1\%) identified stress as a risk factor for hypertension while the same risk factor was also mostly identified by traffic wardens $(76.1 \%)$. Sedentary lifestyle, family history of hypertension and high salt intake were identified by $108(60.0 \%), 106(58.9 \%)$ and $81(45.0 \%)$ of the bankers respectively while these risk factors were identified by 79 (43.9\%), $799(43.9 \%)$ and $119(66.1 \%)$ of traffic wardens respectively. While $86(47.8 \%)$ and

Table 2: Knowledge of Risk Factors for Hypertension
$61(33.9 \%)$ of the bankers respectively do not know whether cigarette smoking and alcohol have an effect on the development of hypertension, $66(38.7 \%)$ and $83(46.1 \%)$ of the bankers knew them as risk factors for hypertension. Also, 48 (26.7\%) and 30 (16.7\%) of the traffic wardens do not know cigarette smoking and alcohol respectively as risk factors for hypertension while $87(48.7 \%)$ and $114(63.3 \%)$ of them did. Obesity was identified by $101(56.1 \%)$ and 86 (47.8\%) of the bankers and traffic wardens respectively as risk factors for hypertension.

Variable

Frequency (\%)

\begin{tabular}{|c|c|c|c|c|c|c|c|}
\hline \multirow[b]{3}{*}{ Cigarette Smoking } & & \multicolumn{3}{|c|}{ Bankers } & \multicolumn{3}{|c|}{ Traffic Wardens } \\
\hline & & \multirow{2}{*}{$\begin{array}{l}\text { Yes } \\
66(38.7)\end{array}$} & \multirow{2}{*}{$\begin{array}{c}\text { No } \\
28(15.6)\end{array}$} & Don't Know & Know & \multicolumn{2}{|c|}{ Don't Know } \\
\hline & & & & $86(47.8)$ & $87(48.3)$ & $45(25.6)$ & $48(26.7)$ \\
\hline Alcohol & $83(46.1)$ & $36(20.0)$ & $61(33.9)$ & & $114(63.3) \quad 36(20.0)$ & $30(16.7$ & \\
\hline Obesity & $101(56.1)$ & $36(20.0)$ & ) $43(23.9$ & & $86(47.8)$ & $1(17.2)$ & $3(35.0)$ \\
\hline High Salt Intake & $81(45.0)$ & $53(29.4)$ & t) $46(26.0)$ & & $119(66.1) \quad 25(13.9)$ & $36(20.0$ & \\
\hline Certain Drugs & & $76(42.2)$ & $52(28.9)$ & $52(28.9)$ & $92(51.1)$ & $25(13.9)$ & $63(35.0)$ \\
\hline Stress & & $76(96.1)$ & $0(0)$ & $7(3.9)$ & $137(76.1)$ & ) 19(10.6) & $24(13.3)$ \\
\hline Emotional Problen & & $137(76.1)$ & $36(20.0)$ & $7(3.9)$ & $129(71.7)$ & $12(6.7)$ & $39(21.7)$ \\
\hline Family History & & $66(58.9)$ & $36(20.0)$ & $38(21.1)$ & $79(43.9)$ & $43(23.9)$ & $58(32.2)$ \\
\hline Sedentary Lifestyle & & $108(60.0)$ & $48(26.7)$ & $24(13.3)$ & $79(43.5)$ & $24(13.3)$ & $77(42.8)$ \\
\hline
\end{tabular}

The cross-tabulation of risk factors for hypertension and occupation showed more bankers (32.2\%) than traffic wardens $(13.3 \%$ were smoking cigarette while $41.7 \%$ of bankers and $22.2 \%$ of traffic wardens were taking alcohol. The majority of the bankers $(65.6 \%)$ had normal BMI while $14.4 \%$ were overweight and $20.0 \%$ were obese. The result was of the same pattern in traffic wardens although there was a slight difference

Table 3: Prevalence of Risk Factors for Hypertension among Respondents

\section{Variable}

\section{Cigarette Smoking}

Yes

No

\section{Alcohol Intake}

Yes

No

\section{Fatty Diet}

Yes

No

\section{Family History}

Positive

Negative

Exercise

Regularly

Occasionally

None

\section{BMI}

Normal

Overweight

Obese

\section{Bankers}

58(32.2)

122(67.8)

75(41.7)

105(58.3)

140(77.8)

40(22.2)

\section{Traffic Wardens}

Frequency

24(13.3)

156(86.7)

40(22.2)

140(77.8)

125(69.4)

55(30.6)
68(37.8)

104(57.8)

8(4.4)

130(72.2)

$\begin{array}{lc}45(25.0) & 68(37.8) \\ 125(69.4) & 104(57.8) \\ 10(5.6) & 8(4.4)\end{array}$

88(48.9)

64(35.6)

28(15.5)

$\begin{aligned} 118(65.6) & 88(48.9) \\ 26(14.4) & 64(35.6) \\ 36(20.0) & 28(15.5)\end{aligned}$

African Health Sciences Vol 14 Issue 3, September 2014 


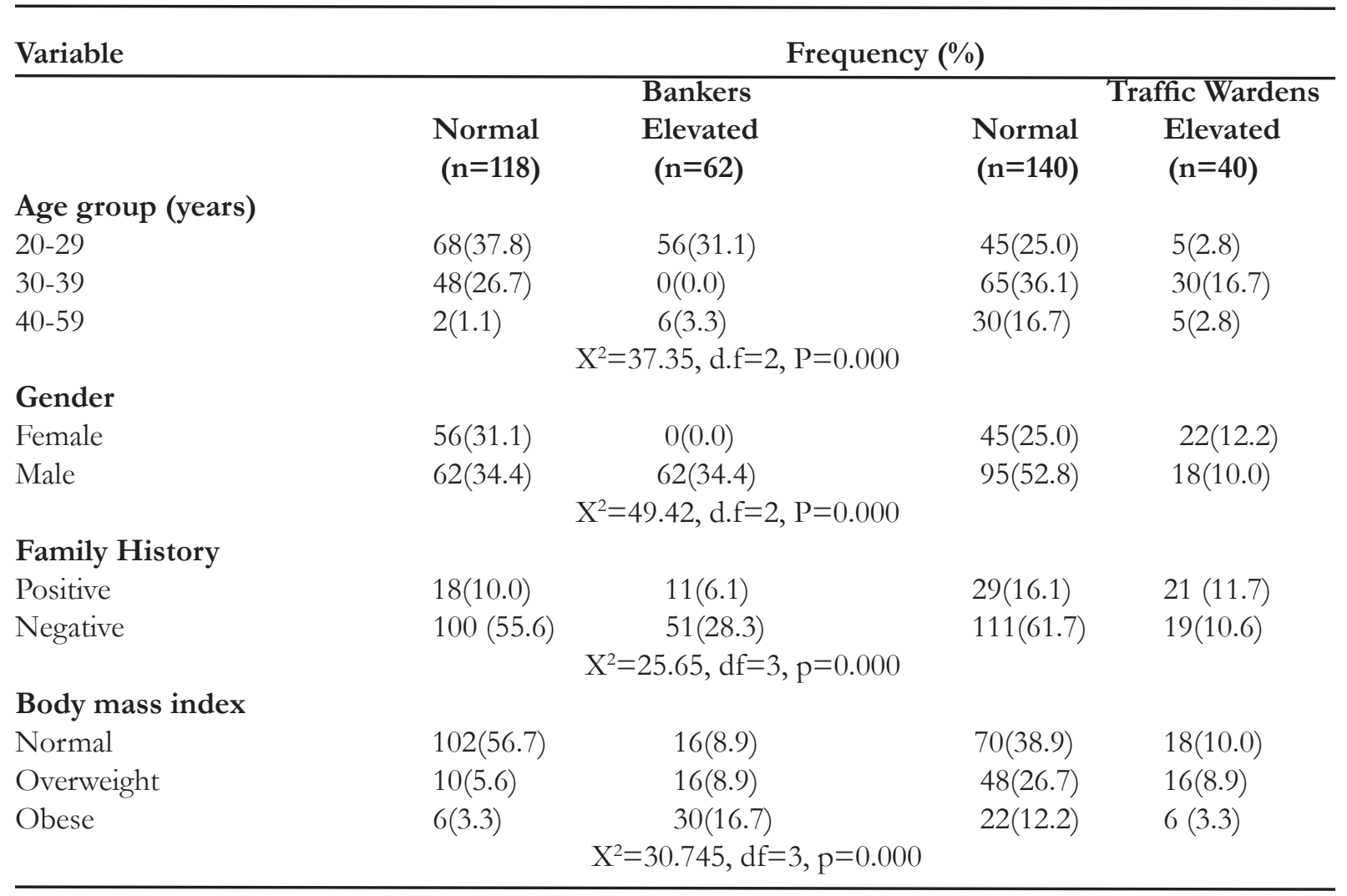

with $48.9 \%$ of them having normal BMI while $35.6 \%$ were overweight and $15.5 \%$ were obese.

Most (69.4\%) of the bankers exercised occasionally, $25 \%$ had regular exercise and $56 \%$ had no exercise.

For the traffic wardens, $57.8 \%, 37.8 \%$ and $44 \%$ had occasional, regular and no exercise respectively. Fatty diet was being regularly taken by $140(77.8 \%)$ of the bankers and $29(16.1 \%)$ of them had positive family history of hypertension. Also, $125(69.4 \%)$ of the traffic wardens were taking fatty diet and $50(27.8 \%)$ had positive family history of hypertension.

The blood pressure pattern of respondents showed statistical significant results with $\mathrm{p}=0.000$ and 118 $(65.6 \%)$ of the bankers had normal blood pressure while $62(34.4 \%)$ had elevated blood pressure. For the traffic wardens, $140(77.8 \%)$ had normal blood pressure $40(22.2 \%)$ had elevated blood pressure.

Table 5: Cigarette smoking, alcohol intake, consumption of fatty foods and Pattern of Blood Pressure among Respondents

Variable $\quad$ Frequency (\%)

\begin{tabular}{lllll}
\hline \multicolumn{2}{c}{ Normal } & Elevated & Normal & $\begin{array}{c}\text { Traffic Wardens } \\
\text { Elevated }\end{array}$ \\
Cigarette Smoking & & & & \\
Smokers & $26(14.4)$ & $32(17.8)$ & $18(10.0)$ & $6(3.3)$ \\
Non-smokers & $92(51.1)$ & $30(16.7)$ & $122(67.8)$ & $34(18.9)$ \\
Total & $118(65.6)$ & $62(34.4)$ & $140(77.8)$ & $40(22.2)$ \\
& $\mathrm{X}^{2}=38.5$ & $\mathrm{df}=3$ & $\mathrm{p}=0.000$ & \\
Alcohol intake & & & & \\
Yes & $27(15.0) 48(7.8)$ & $34(18.9)$ & $6(3.3)$ & \\
No & $91(50.6) 14(7.8)$ & $106(58.9)$ & $34(18.9)$ & \\
Total & $118(65.6)$ & $62(34.4)$ & $140(77.8)$ & $40(22.2)$ \\
& $\mathrm{X}^{2}=72.49$ & $\mathrm{df}=3$ & $\mathrm{p}=0.000$ & \\
Consumption of fatty foods & & & & \\
Yes & & & & \\
No & $88(48.9) 52(28.9) 97(53.9)$ & $28(15.6)$ & \\
Total & $30(16.7) 10(5.6)$ & $43(23.9)$ & $12(6.7)$ & \\
& $118(65.6)$ & $62(34.4)$ & $140(77.8)$ & $40(22.2)$ \\
\hline
\end{tabular}




\section{Discussion}

In this study, $34.4 \%$ of the bankers had BMI above normal while $51.1 \%$ of the traffic wardens had BMI above normal. This is almost similar to a study done in Brazil in which industry workers who seem to engage in more rigorous activities had $63 \%$ of them being overweigh. ${ }^{9}$ This could be due to an increase muscle mass built by rigorous activity. A finding of smoking habit in $32.2 \%$ and $13.3 \%$ of bankers and traffic wardens respectively in this study as against $23.9 \%$ recorded among students in a Polish postgraduate school $^{8}$ showed a similar trend.

Over $25 \%$ of the bankers do not know whether cigarette smoking, alcohol or high salt intake is a risk factor for hypertension and at least $20 \%$ of them do not know of obesity being a risk factor while at least $25 \%$ of the traffic wardens do not know if cigarette smoking, obesity, family history or sedentary lifestyle is a risk factor for hypertension. This is also similar to a study done in North Carolina ${ }^{11}$ in which $22 \%$ of the respondents were not aware of any preventive measures for hypertension. The implication of this is that this category of people in the population will not likely actively seek medical intervention or bother to avoid the modifiable risk factors for hypertension.

This study has also revealed that the bankers generally had more knowledge than traffic wardens about the risk factors for hypertension. This is deduced from the findings as more bankers had knowledge of 5 risk factors while traffic wardens had more knowledge of 4. This supports the findings in previous studies that higher socioeconomic status and level of schooling are factors affecting the knowledge of risk factors for hypertension. ${ }^{12,13}$

The prevalence of hypertension in this study was $34.4 \%$ in bankers and $22.2 \%$ in traffic wardens. This is in keeping with findings in previous studies ${ }^{3}$ in which the prevalence in bankers and other similar occupations of sedentary nature has been found to be higher. ${ }^{3,13-15}$ Elevated blood pressure was found in most overweight (16-36) and obese (30 of 36) bankers. This is similar to previous findings which showed that an increase in BMI is a significant factor affecting blood pressure pattern. ${ }^{15}$ This trend was however not noticed in traffic wardens in this study as a relatively lesser percentage of overweight and obese traffic wardens had elevated blood pressure. This may be due to a balance created by their higher rate of physical activity. Also, a relatively lesser percentage $(38.7 \%)$ of bankers had knowledge of cigarette smoking as a risk factor for hypertension. This may be responsible for the higher percentage of smokers among bankers $(32.2 \%)$ than traffic wardens $(13.3 \%)$ thereby indicating that the latter's knowledge of the dangers associated with cigarette smoking made them avoid it.

\section{Conclusion}

The prevalence of hypertension in this study was more in bankers $(34.4 \%)$ in bankers than in traffic wardens $(22.2 \%)$. Despite having more knowledge about the risk factors of hypertension than traffic wardens, the bankers in this study had a higher prevalence of hypertension when compared with the traffic wardens. This showed a lack of correlation between their level of knowledge and its effect on their blood pressure pattern. This is probably due to the sedentary nature of their job which has a strong impact on the increase in blood pressure in a greater percentage of bankers. Also, the levels of knowledge of risk factors of hypertension in bankers and traffic wardens are not adequate to satisfactorily reduce the prevalence of hypertension generally. Workers in the banking industry as well as traffic wardens should be better educated about the risk factors of hypertension and bankers should be encouraged to create time for exercise.

\section{References}

1. Kearney PM, Whelton M, Reynold K, Muntner P, Whelton PK, He J. Global burden of hypertension: Analysis of worldwide data. Lancet 2005;365: 217-223.

2. Nakamura H, Kouda K, Fan W, Takeuchi H. Cardiovascular risk factors in a tourist town: Association with job-related factors. Journal Physiol Anthropol Appl Human Science 2002; 21 (5): 223-227.

3. Maroof KA, Parasher P, Bansal R, Ahmad S. A study on hypertension among the bank employees of Meerut district of utta Pradesh. IJPH 2007; 51: 225-227.

4. Saheed O, Gupta V, Dhawan N, Streja L, Shin JS, Ku M, Bhoi S, Verma S. Knowledge of modifiable risk factors of Coronary Atherosclerotic Heart Disease (CASHD) among a sample in India. BMC International bealth and buman rights 2009;9:2.

5. Fauvel J , M'Pio I, Quelin P, Rigaud J, Laville M, Ducher M. Neither perceived job stress nor individual cardiovascular reactivity predict high blood pressure. Hypertension 2003; 42;1112-1116.

6. Hartung D, Stadeler M, Grieshaber R, Keller S, Jahreis G. Work and diet-related risk factors of cardiovascular diseases: comparison of two occupation groups. JOMT 2010; 5: 4.

7. Sodjinou R, Agueh V, Fayomi B, Delisle H. Obesity and cardio-metabolic risk factors in urban adults of Be- 
nin: relationship with socio-economic status, urbanisation, and lifestyle patterns. BMC Public Health2008;4:84. 8. Poreba R, Gac P, Zawadzki M, Poreba M, Derkacz A, Pawlas $\mathrm{K}$ et al. Lifestyle and cardiovascular risk factors among students of Wroclaw postgraduate schools. Pol Arch Med Wewn 2008; 118 (3): 102-110.

9. Soures R, Cassani L, Nobre F, Filho AP, Schmidt A. Prevalence of cardiovascular risk factors in a population of Brazillian workers. ArqBras Cardiol 2009;92(1):15-21 10. Guimont C, Brisson C, Dagenais GR, Milot A, Vezina M, Masse B et al. Effect of job strain on blood pressure: A prospective study of male and femalewhitecollar workers. Am J Pub Health 2006;96(8): 1436-1443. 11. Viera AJ, Cohen LW, Mitchell CM, Sloane PD. High blood pressure knowledge among primary care patients with known hypertension: a North Carolina Family Medicine Research Network (NC-FM-RN) study. J $A M$ Fam Med2008;21(4):300-8.

12. Borges TT, Rombaldi AJ, Knuth AG, Hallal PC. Knowledge on risk factors for chronic diseases: a population-based study. Cad Saude Publica 2009; 25(7):151120.

13. Tsutsumi A, Kayaba K, Tsutsumi K, Igarashi M. Association between job strain and prevalence of hypertension: a cross sectional analysis in a Japanese working population with a wide range of occupations: the
Jichi medical school cohort study. Occup Environ Med 2001;58:367-373.

14. Martinez CM, Latorre M. Risk factors for hypertension and diabetes mellitus in metallurgic and siderurgic company's workers. Arc Bras Cardiol 2006;88:236-240. 15. Wenzel D, de Souza JP, de Souza SB. Prevalence of arterial hypertension in young military personnel and associated factors. Rev Saude Publica 2009;43(5).

16. Schumann B, Seidler A, Kluttig A, werdan K, Haerting J, Halina K. Association of hypertension with prevalent hypertension in the elderly East German population: an exploratory cross-sectional analysis. International Archive of Occupation and Environment.DOI: 10.1007/s00420-010-0584-5

17. Ekore RI, Ajayi IO, Arije A. Case finding for hypertension in young adult patients attending a missionary hospital in Nigeria. AHS 2009 ;(3):193-199.

18. Mendez-Chacon E, Santamaria-Ulloa C, Rosero Bixby L. Factors associated with hypertension prevalence, unawareness and treatment among costa Rican elderly. BMC Public Health 2008;8:275.

19. Bovet P, Ross AG, Gervasoni J, Mkamba M, Mtasiwa $\mathrm{DM}$, Lengeler $\mathrm{C}$ et al. Distribution of blood pressure, body mass index and smoking habits in the urban population of Dar es Salaam, Tanzania, and associations with socioeconomic status. IJE 2002; 31:240-247. 